University of Wollongong

Research Online

Faculty of Social Sciences - Papers (Archive) Faculty of Arts, Social Sciences \& Humanities

2014

Investigating the reliability and validity of candidate psychophysiological endophenotypes of affective processing

David A. Camfield

University of Wollongong, camfield@uow.edu.au

Rodney J. Croft

University of Wollongong, rcroft@uow.edu.au

Keith A. Wesnes

Swinburne University of Technology

Sarah Boyall

University of Wollongong

Monique Taylor

University of Wollongong

See next page for additional authors

Follow this and additional works at: https://ro.uow.edu.au/sspapers

Part of the Education Commons, and the Social and Behavioral Sciences Commons

Research Online is the open access institutional repository for the University of Wollongong. For further information contact the UOW Library: research-pubs@uow.edu.au 


\title{
Investigating the reliability and validity of candidate psychophysiological endophenotypes of affective processing
}

\author{
Abstract \\ Abstract presented at The 17th World Congress of Psychophysiology (IOP2014) of the International \\ Organization of Psychophysiology (IOP) Hiroshima, Japan, September 23rd to 27th, 2014 \\ Keywords \\ processing, affective, endophenotypes, psychophysiological, candidate, reliability, validity, investigating \\ Disciplines \\ Education | Social and Behavioral Sciences

\section{Publication Details} \\ Camfield, D. A., Croft, R., Wesnes, K., Boyall, S., Taylor, M., Tasca, R. \& Kornfield, E. (2014). Investigating the \\ reliability and validity of candidate psychophysiological endophenotypes of affective processing. \\ International Journal of Psychophysiology, 94 (2), 245.

\section{Authors} \\ David A. Camfield, Rodney J. Croft, Keith A. Wesnes, Sarah Boyall, Monique Taylor, Rachael Tasca, and \\ Emma Kornfield
}




\section{Investigating the reliability and validity of candidate psychophysiological endophenotypes of affective processing}

David A. Camfield ${ }^{a}$, Rodney Croft ${ }^{a}$, Keith Wesnes ${ }^{b}$, Sarah Boyall ${ }^{c}$, Monique Taylor ${ }^{c}$, Rachael Tasca ${ }^{c}$, Emma Kornfield ${ }^{\mathrm{C}}$

${ }^{a}$ School of Psychology, Illawarra Health \& Medical Research Institute, University of Wollongong, Australia

${ }^{b}$ Wesnes Cognition, Swinburne University of Technology, Northumbria

University, United Kingdom

${ }^{c}$ School of Psychology, University of Wollongong, Australia

Background: A number of studies have been conducted in recent years documenting electrophysiological and autonomic correlates of affective processing in healthy, as well as clinical, populations. Of particular interest to researchers in this area is the development endophenotypes/biomarkers that may be used as objective metrics for the diagnosis and selection of treatment alternatives in mood disorders.

Methods: Five computerized experimental tasks are to be assessed for their reliability and validity in eliciting psychophysiological measures in a healthy adult population (combined $\mathrm{N}$ = 120): (i) An Emotional Sternberg task using positive, negative and neutrally valenced word triplets will be used to investigate the affect of emotionally distracting material on eventrelated synchronization (ERS) during working memory performance, (ii) loudness dependence of the Auditory Evoked Potential will be investigated in relation to individual differences on the Positive-Negative Affect schedule (PANAS), (iii) a visual Object Pattern Separation test will be used to investigate differences in ERP amplitudes associated with memory retrieval for pictures which are highly similar ( 'lure' images) in comparison to previously presented images. (iv) A differential fear conditioning paradigm using neutral faces paired with aversive images from the International Affective Picture System (IAPS) and startle probes will be used to investigate the affect of fear conditioning on early face-related ERP components, including the N170. (v) Using a battery of 300 IAPS images, in combination with intermittent startle probes, individual differences in skin conductance response (SCR), zygomator/corrugator EMG, and startle P3 amplitude will be investigated in relation to positive and negatively-valenced highly arousing imagery.

Results/conclusions: Data collection was commenced in April 2014, with preliminary data available by August 2014. On the basis of these results in a healthy population, the most reliable endophenotypes will be subsequently selected for investigating deficits in affective processing in patients with Major Depressive Disorder (MDD). 